\title{
Green stability indicating UV- spectrophotometric techniques for estimation of tenofovir alafenamide in bulk form and dosage forms
}

\author{
Noha S. Said ${ }^{1}$; Zeinab Adel Nasr ${ }^{1, *}$ and Sawsan A. Abdel-Razeq ${ }^{1}$ \\ ${ }^{1}$ Pharmaceutical Analytical Chemistry Department, Faculty of Pharmacy (Girls), Al-Azhar University, Cairo 11754, Egypt \\ * Correspondence: zeinabadel@azhar.edu.eg; Tel.: (00201005620951)
}
Article history: Received 22-12-2020.
Revised 04-01-2020
Accepted 09-01-2021

\begin{abstract}
Four simple, precise and sensitive UV- spectrophotometric procedures were achieved for estimation of tenofovir alafenamide in the presence of its alkaline degradate. Dual wavelength was the first one which based on determination of the drug at $235.5 \mathrm{~nm}$ and $261.5 \mathrm{~nm}$. First - derivative spectrophotometric method was the second one which the amplitude values were measured at $274 \mathrm{~nm}$ using $\Delta \lambda$ of $8 \mathrm{~nm}$ and a scaling factor of 20 . Third one was ratio difference which peak's amplitudes ratio spectra difference of tenofovir alafenamide was measured between $261.5 \mathrm{~nm}$ and $252 \mathrm{~nm}$ using devisor of $10 \mu \mathrm{g} \mathrm{mL}$ of its alkaline degradate. While the last method was a first derivative of ratio spectra using $\Delta \lambda=8 \mathrm{~nm}$ and a scaling factor $=10$ to measure the amplitude at $275.6 \mathrm{~nm}$. The linearity range was $5-35 \mu \mathrm{g} \mathrm{mL} \mathrm{m} \mathrm{all}^{-1}$ procedures. The suggested procedures were effectively utilized for the estimation of the cited drug in bulk form as well as its dosage forms. According to ICH guidelines, all procedures were validated. Moreover, Analytical eco-scale and Green Analytical Procedure Index (GAPI) were used to estimate the greenness of the suggested methods compared with a reported one as two assessment tools.
\end{abstract}

Keywords: Green; Stability indicating; degradate; Tenofovir Alafenamide; UV- spectrophotometry.

\section{INTRODUCTION}

Tenofovir alafenamide (TAF); chemically known as isopropyl (2S)-2[[[(1R)-2-(6-aminopurin-9-yl) -1- methyl-ethhoxy] methyl-phenoxy phoshoryl] amino] propionate is a nucleoside reverse transcriptase inhibitors (NRTIs) and a novel ester prodrug of the antiretroviral tenofovir. Tenofovir alafenamide is related to a HIV drugs groups which called nucleoside reverse transcriptase inhibitors (NRTIs) which acts by blocking reverse transcriptase, to prevent HIV from multiplying ${ }^{1}$. The literature revealed that various predetermination methods of tenofovir alafenamide either alone or with other drugs by spectroscopic methods ${ }^{2-5}$, HPLC ${ }^{6-15}$, LC ${ }^{16}$, LC- MS/ MS ${ }^{17,18}$. However, a few stability indicating methods have been carried for determination of the drug using spectrophotometric method ${ }^{19,20}$, HPLC ${ }^{21-25}$ and RP-UPLC-PDA in multidrug combination ${ }^{26}$. Green chemistry's main idea is seen as a tool for enhancing reasonable development in the method of analysis. In the field of analytical chemistry, many studies have been conducted to reduce the cost and to avoid the threats of analytical procedures. In order to make chemical analysis green, green chemistry is used as it confirms the use of safe, less toxic and gentler solvents or removal of solvents and the use of small quantities of reagents ${ }^{27}$. Therefore, this work focused on the development of first eco-friendly, simple, fast, economic and delicate UV Spectroscopic procedures for estimation of tenofovir alafenamide in presence of its alkaline degradate as well as in its dosage forms. The greenness of the four established methods as well as the reported one were evaluated by using analytical Eco-Scale and Green Analytical Procedure Index (GAPI) methods to confirm the effect of each approach on the environment.

\section{METHODS}

\subsection{Instruments}

Shimadzu double beam UV-visible spectrophotometer 1601 PC Ultra with matched pair supplied with $10 \mathrm{~mm}$ matched quartz cells (Tokyo, Japan), with UV-Probe personal spectroscopy with software of version 2.10.

\subsection{Materials and reagents}

Tenofovir alafenamide, B.N. TV0020516 was obtained from PHARMED Healthcare; Cairo, Egypt. The purity was reported to be $97.60 \%$ as stated by the supplier. Methanol (Sigma-Aldrich, Darmstadt, Germany). $\mathrm{NaOH}, \mathrm{HCL}$ and $\mathrm{H}_{2} \mathrm{O}_{2}$, (Qualikems fine chemical Pvt. Ltd, India). Freshly distilled water was used through all steps of the work. 


\subsection{Dosage form}

HEPBEST $\AA$ tablets; B. N. 8069912, one tablet badged to contain $25 \mathrm{mg}$ tenofovir alafenamide which produced from Mylan Company for Pharmaceutical Industry, USA.

\subsection{Standard solutions}

In methanol, tenofovir alafenamide (1 mg $\mathrm{mL}^{-1}$ ) was prepared to obtain the normal stock solution. In order to achieve a final concentration of $100 \mu \mathrm{g} \mathrm{mL}{ }^{-1}$, the operating standard solutions were prepared with further dilution of the stock solution with the same solvent.

\subsection{Degraded samples}

A weight of $100 \mathrm{mg}$ of pure tenofovir alafenamide was accurately weighed and refluxed with $25 \mathrm{~mL}$ of $3 \mathrm{~N} \mathrm{NaOH}$ for $3 \mathrm{~h}$ or with $25 \mathrm{~mL} 5 \mathrm{~N}$ $\mathrm{HCl}$ for $4 \mathrm{~h}$ at $100{ }^{\circ} \mathrm{C}$ for alkaline and acidic degradation, respectively. Both solutions were cooled and neutralized at $\mathrm{pH} \mathrm{7,} \mathrm{then} \mathrm{evaporated}$ until dryness under vacuum. The obtained residues were extracted three times each with $25 \mathrm{~mL}$ methanol then filtered into two separate 100- $\mathrm{mL}$ volumetric flasks and diluted to the volume with methanol to obtain a stock solution claimed to contain alkaline or acid degradate derived from 1 $\mathrm{mg} \mathrm{mL} \mathrm{m}^{-1}$ intact drug.

\subsection{Procedures}

\subsubsection{Spectral characteristics}

Tenofovir alafenamide's zero-order spectra and its alkaline and acidic degradate were scanned over the $200-400 \mathrm{~nm}$ range, as shown in Figure 1.

\subsubsection{Constitution of calibration curves}

From the drug working standard solutions (100 $\mu \mathrm{g} \mathrm{mL} \mathrm{m}^{-1}$ ), different volumes equivalent to (5-35) $\mu \mathrm{g}$ tenofovir alafenamide were transferred to a series of $10 \mathrm{~mL}$ volumetric flasks and the volume was completed with the same solvent. The absorption spectrum of prepared solutions has been scanned from 200 to $400 \mathrm{~nm}$ and stored in the computer to be manipulated by the following procedures.

DW method: Absorbance of the above solutions were measured between 235.5 and $261.5 \mathrm{~nm}$ where the difference in absorbance of the alkaline degradate is zero (Figure 1).

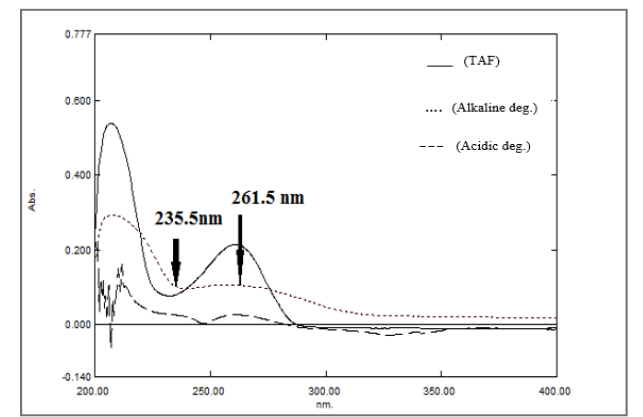

Figure (1): Zero absorption spectrum of $10 \mu \mathrm{g} \mathrm{mL}^{-1}$ tenofovir alafenamide overlaid with $10 \mu \mathrm{g} \mathrm{mL}^{-1}$ of its alkaline degradate and its acidic degradate.

\section{${ }^{1} D$ method:}

For the above solutions, the first absorption spectrum derivative stored in the computer was reported using $\Delta \lambda=8 \mathrm{~nm}$ and a scaling factor $=20$; At $274 \mathrm{~nm}$, the amplitude values were calculated (Figure 2).

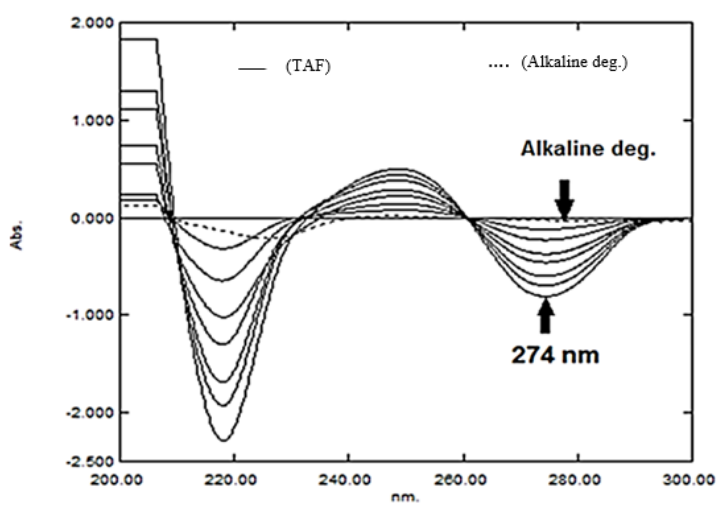

Figure(2): First derivative spectra of $\left(5-35 \mu \mathrm{g} \mathrm{mL} \mathrm{m}^{-1}\right)$ tenofovir alafenamid in presence of its alkaline degradate in methanol.

\section{RD method:}

The stored zero order spectra of tenofovir alafenamide solutions were divided by the spectrum of $10 \mu \mathrm{g} \mathrm{mL} \mathrm{m}^{-1}$ of its alkaline degradate. The recorded difference values in peak amplitudes between 261.5 and $252 \mathrm{~nm}$ were calculated (Figure 3).

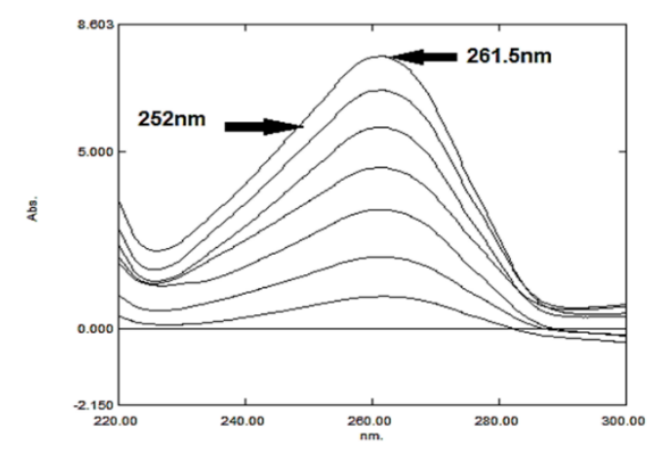

Figure(3): Smoothed ratio spectra of tenofovir alafenamide $\left(5-35 \mu \mathrm{g} \mathrm{mL}^{-1}\right)$ using $\left(10 \mu \mathrm{g} \mathrm{mL}^{-1}\right)$ of its alkaline degradate as a divisor. 
${ }^{1} \boldsymbol{D} \boldsymbol{R}$ method: ${ }^{1} \mathrm{D}$ with $\lambda=8 \mathrm{~nm}$ and scaling factor $=10$ of the previously reported ratio spectra and the amplitudes of the resulting spectra were calculated at $275.6 \mathrm{~nm}$ (Figure 4). In each of the above procedures, construction of calibration curve between response and drug concentration was done and regression equation was computed.

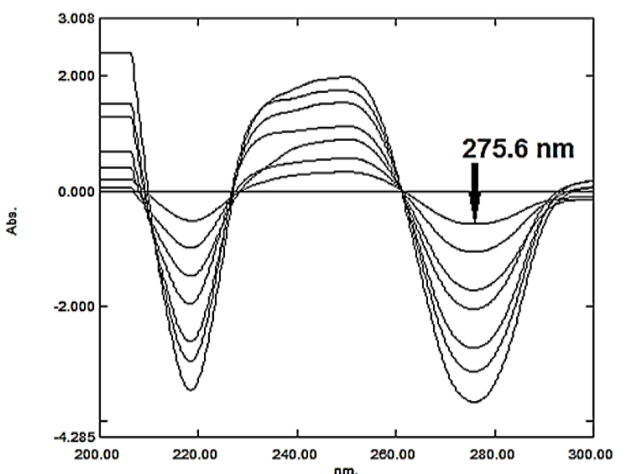

Figure (4): First derivative of ratio spectra of tenofovir alafenamide $\left(5-35 \mu \mathrm{g} \mathrm{mL}^{-1}\right)$ using $\left(10 \mu \mathrm{g} \mathrm{mL}^{-1}\right)$ of its alkaline degradate as a divisor.

\subsubsection{Application to laboratory prepared mixtures}

Into a series of $10 \mathrm{~mL}$ volumetric flasks containing $(0.28-0.07 \mathrm{mg})$ of the degraded drug, aliquots containing $(0.07-0.28 \mathrm{mg})$ of intact tenofovir alafenamide solution were transferred to the label and then diluted with the solvent. The spectrum was calculated and stored on the computer for these mixtures. The protocol for each process was then applied and the concentrations of the drug in the prepared mixtures were calculated from the corresponding regression equation.

\subsubsection{Application to dosage forms}

Ten HEPBEST ${ }^{\circledR}$ tablets containing $25 \mathrm{mg}$ of tenofovir alafenamide were well weighed, powdered and blended. A quantity equal to $100 \mathrm{mg}$ of the drug was transferred to a volumetric flask of $100 \mathrm{~mL}$ and diluted with the same solvent in the label. The flask was sonicated for $15 \mathrm{~min}$ then filtered. The clear filtrate was claimed to contain $1 \mathrm{mg} \mathrm{mL}{ }^{-1}$ of tenofovir alafenamide. Ten $\mathrm{mL}$ of the filtrate was 10 folds diluted with the solvent to obtain a solution containing $100 \mu \mathrm{g} \mathrm{mL}^{-1}$ of the drug and analyzed by the developed procedures using the previously mentioned conditions. The concentration of the studied drug was calculated from the corresponding regression equation.

\section{RESULTS}

The goal of this work is to develop a new validated green stability indicating UV- spectroscopic methods capable of determining tenofovir alafenamide with appropriate sensitivity and selectivity in the presence of its alkaline degradation, either in bulk form or in its dosage forms.

\subsection{Methods validation}

Validation of the developed methods in compliance with ICH Guidelines ${ }^{28}$.

3.1.1. Linearity and range - The calibration curves for the suggested methods were developed under the mentioned experimental conditions by plotting the response versus tenofovir alafenamide concentrations in $\mu \mathrm{g} \mathrm{mL}^{-1}$. For the cited compound, the regression plots were found to be linear over the 5-35 $\mu \mathrm{g} \mathrm{mL}^{-1}$ range. For each of the suggested methods, the spectrum and equations of linear regression were computed and shown in Table 1.

3.1.2. Detection and Quantitation Limits - Based on LOD $(3.3 \mathrm{SD} / \mathrm{S})$ and LOQ $(10 \mathrm{SD} / \mathrm{S})$, the sensitivity of the proposed methods was assessed. The results shown in Table 1.

3.1.3. Accuracy - Three separate concentrations of pure tenofovir alafenamide samples covering the linearity spectrum, each in triplicate, were estimated. From their corresponding regression equations, concentrations were calculated. Good $\% \mathrm{R}$ $(99.69 \%, 99.40 \%, 99.77 \%$ and $99.80 \%)$ for the proposed methods; respectively, as listed in Table 1, confirms excellent accuracy.

3.1.4. Precision - Three concentrations of tenofovir alafenamide $\left(10,20,30 \mu \mathrm{g} \mathrm{mL}^{-1}\right)$ were tested, each in triplicate, within one day and on three successive days using the proposed UV- methods. RSD\% of repeatability amounted to be $0.60 \%, 0.62 \%, 0.79 \%$ and $0.58 \%$, While intermediate precision computed to be $1.38 \%, 0.95 \%, 1.21 \%$ and $0.84 \%$ for each established methods, respectively as shown in Table 1.

3.1.5. Selectivity - It was verified by applying the established processes along with its alkaline degradation to laboratory prepared mixtures of the intact drug. Good recoveries of intact tenofovir alafenamide were obtained by the proposed methods in the presence of up to $80 \%$ of its degradate, as shown in Table 2.

\subsection{Application to dosage forms}

The methods developed have been successfully used in the estimation of tenofovir alafenamide to HEPBEST ${ }^{\circledR}$ tablets. The findings were appropriate and gave high reliability and good agreement with labelled quantity. The proposed methods were then tested using the standard addition technique which there was no interference from excipients and additives was observed, as shown in Table 3 . The findings obtained were statistically compared to those obtained by applying the t-test and F-test to the reported RPHPLC method at 95\% confidence level ${ }^{29}$, showing no significant difference between 
the established and reported methods, as shown in Table 4. The proposed procedures are therefore sufficiently detailed and effective. The developed
UV-spectrophotometric techniques, however, were more sensitive and more selective.

Table 1: Assay parameters and validation results obtained by the proposed UV- spectrophotometric methods for determination of tenofovir alafenamide.

\begin{tabular}{|c|c|c|c|c|}
\hline Method parameters & DW & ${ }^{1} \mathbf{D}$ & RD & ${ }^{1} \mathbf{D R}$ \\
\hline Wavelength (nm) & $261.5-235.5$ & 274 & $261.5-252$ & 275.6 \\
\hline Linearity range $\left(\mu \mathrm{g} \mathrm{mL} \mathrm{L}^{-1}\right)$ & $5-35$ & $5-35$ & 5-35 & $5-35$ \\
\hline \multicolumn{5}{|l|}{$\underline{\text { Regression equation }}$} \\
\hline Slope $\pm \operatorname{SD}\left(\mathbf{S}_{\mathbf{Y}}\right)$ & $0.0274 \pm 0.005$ & $0.023 \pm 0.003$ & $0.0360 \pm 0.0004$ & $0.1052 \pm 0.0012$ \\
\hline Intercept $\pm \mathbf{S D}\left(\mathbf{S}_{\mathbf{X}}\right)$ & $0.00457 \pm 0.0012$ & $0.007 \pm 0.0024$ & $0.0061 \pm 0.010$ & $0.0077 \pm 0.0072$ \\
\hline SD of residual $\left(\mathbf{S}_{\mathbf{Y X}}\right)$ & 0.527 & 0.371 & 0.910 & 0.517 \\
\hline Correlation coefficient (r) & 0.9992 & 0.9996 & 0.9995 & 0.9996 \\
\hline Accuracy $($ mean \pm SD) & $99.69 \pm 0.38$ & $99.40 \pm 0.21$ & $99.77 \pm 0.38$ & $99.80 \pm 0.78$ \\
\hline \multicolumn{5}{|l|}{ Precision ( $\pm \%$ RSD) } \\
\hline *Repeatability & 0.60 & 0.62 & 0.79 & 0.58 \\
\hline *Intermediate precision & 1.38 & 0.95 & 1.21 & 0.84 \\
\hline LOD & 0.144 & 0.344 & 0.916 & 0.225 \\
\hline LOQ & 0.437 & 1.04 & 2.77 & 0.684 \\
\hline
\end{tabular}

$*_{\mathrm{n}}=$ nine determinations.

Table 2: Determination of tenofovir alafenamide in laboratory prepared mixtures with its alkaline degradate by the proposed UV- spectrophotometric methods.

\begin{tabular}{|c|c|c|c|c|c|}
\hline Intact & Degradate & DW & ${ }^{1} \mathbf{D}$ & RD & ${ }^{1} \mathbf{D R}$ \\
\hline$\left(\mu \mathrm{g} \mathrm{mL} L^{-1}\right)$ & $\left(\mu \mathrm{g} \mathrm{mL} \mathbf{L}^{-1}\right)$ & $\%$ of intact & $\%$ of intact & $\%$ of intact & $\%$ of intact \\
\hline 7 & 28 & 100.20 & 102.00 & 97.40 & 100.60 \\
\hline 10 & 25 & 99.81 & 97.70 & 101.20 & 98.60 \\
\hline 15 & 20 & 98.6 & 98.40 & 97.93 & 97.93 \\
\hline 20 & 15 & 101.05 & 99.05 & 99.15 & 100.90 \\
\hline 25 & 10 & 101.24 & 99.44 & 97.56 & 100.24 \\
\hline 28 & 7 & 99.20 & 97.96 & 99.56 & 100.33 \\
\hline Mean $\% \pm$ SD & & $100.02 \pm 1.03$ & $99.09 \pm 1.57$ & $98.80 \pm 1.46$ & $99.77 \pm 1.20$ \\
\hline
\end{tabular}


Table 3: Assay of tenofovir alafenamide in dosage forms and application of standard addition technique for determination of the drug by the proposed UV- spectrophotometric methods.

\begin{tabular}{|c|c|c|c|c|c|}
\hline & & \multicolumn{4}{|c|}{ Tenofovir alafenamide } \\
\hline & & DW & ${ }^{1} \mathbf{D}$ & RD & ${ }^{1} \mathbf{D R}$ \\
\hline \multirow[t]{2}{*}{$\begin{array}{l}\text { HEPBEST } ® \\
\text { tablets }\end{array}$} & Mean $\% \pm$ SD & $99.31 \pm 0.79$ & $99.15 \pm 1.28$ & $99.86 \pm 1.51$ & $99.21 \pm 0.89$ \\
\hline & \multicolumn{5}{|c|}{ Standard addition technique } \\
\hline \multirow[t]{3}{*}{$\begin{array}{c}\text { Dosage form } \\
\text { taken } \\
\left(\mu \mathrm{g} \mathrm{mL} \mathbf{~}^{-1}\right) \\
\end{array}$} & $\begin{array}{c}\text { Pure } \\
\text { added } \\
\left(\mu \mathrm{g} \mathrm{mL}^{-1}\right) \\
\end{array}$ & \multicolumn{4}{|c|}{$\%$ recovery $^{a}$} \\
\hline & & DW & ${ }^{1} \mathbf{D}$ & RD & $\mathbf{D R}^{1}$ \\
\hline & 5 & 97.80 & 100.20 & 97.80 & 102.60 \\
\hline \multirow[t]{3}{*}{10} & 10 & 97.91 & 98.30 & 97.81 & 100.21 \\
\hline & 15 & 100.15 & 99.40 & 100.53 & 99.53 \\
\hline & 25 & 99.30 & 98.60 & 99.20 & 100.65 \\
\hline Mean $\% \pm$ SD & & $98.79 \pm 1.13$ & $99.13 \pm 0.86$ & $98.84 \pm 1.31$ & $100.75 \pm 1.32$ \\
\hline
\end{tabular}

${ }^{\mathrm{a}}$ mean of 3 determinations

Table 4: Statistical comparison for the results obtained by the proposed methods and the reported method ${ }^{21}$ for determination of tenofovir alafenamide.

\begin{tabular}{|c|c|c|c|c|c|}
\hline \multirow[t]{2}{*}{ Parameters } & \multicolumn{5}{|c|}{ Proposed methods } \\
\hline & DW & ${ }^{1} \mathbf{D}$ & RD & ${ }^{1} \mathbf{D R}$ & Reported Method ${ }^{21}$ \\
\hline $\begin{array}{l}\text { Linearity range } \\
\left(\mu \mathrm{g} \mathrm{mL}^{-1}\right)\end{array}$ & $5-35$ & $5-35$ & $5-35$ & $5-35$ & $10-150$ \\
\hline $\mathbf{N}$ & 5 & 5 & 5 & 5 & 5 \\
\hline Mean\% & 99.31 & 99.15 & 99.86 & 99.21 & 100.29 \\
\hline SD & 0.790 & 1.28 & 1.51 & 0.89 & 1.53 \\
\hline Variance & 0.62 & 1.63 & 2.28 & 0.79 & 2.34 \\
\hline Student's t-test (2.306) & 1.34 & 1.38 & 0.35 & 1.75 & --- \\
\hline F - value (6.388) & 3.74 & 1.42 & 1.02 & 2.91 & --- \\
\hline
\end{tabular}

-The values between parenthesis are the theoretical values of $\mathrm{t}$ - and $\mathrm{F}$-test at $\mathrm{P}=0.05$

-Ref ${ }^{21}$ stability indicating assay method for the determination of tenofovir alafenamide tablets by RP-HPLC with UV detection was $260 \mathrm{~nm}$. 


\section{DISCUSSION}

\subsection{Forced degradation}

Study of stress degradation of tenofovir alafenamide was done by refluxing the drug with $\mathrm{NaOH}, \mathrm{HCl}$ and aqueous $\mathrm{H}_{2} \mathrm{O}_{2}$ for different time intervals or under thermal conditions. The drug not affected by aqueous $\mathrm{H}_{2} \mathrm{O}_{2}$ or thermal check. Full degradation was reached only by refluxing the drug with $3 \mathrm{~N} \mathrm{NaOH}$ for $3 \mathrm{hr}$ or with $5 \mathrm{~N} \mathrm{HCl}$ for $4 \mathrm{hr}$. This was certified by absence of band in the area of the degradate corresponding to the band of the intact drug.

Degradation products were supported by IR using $\mathrm{KBr}$ disc as follows; a wide band was observed for two (NH) groups in the IR spectrum of the pure drug at $3326 \mathrm{~cm}^{-1}$. Bands for both the aromatic $(\mathrm{CH})$ at $2982 \mathrm{~cm}^{-1}$ and ester carbonyl group at $1744 \mathrm{~cm}^{-1}$ in were also determined. The alkaline degradate, showed a wide band of phosphoric $(\mathrm{OH})$ group at $3445 \mathrm{~cm}^{-1}$ and lacked the $\mathrm{CH}$ aromatic band. While in acidic degradate, IR spectrum revealed absence of the $\mathrm{C}=\mathrm{O}$ band of the ester moiety at $1744 \mathrm{~cm}^{-1}$ and presence of phosphoric $(\mathrm{OH})$ group broad band at $3423 \mathrm{~cm}^{-1}$ as shown in Figure 5 (a-c). Degradation was also confirmed by MS as follows; the intact drug displayed spectroscopic molecular ion peak electronic ionization mass at $\mathrm{m} / \mathrm{z}=476$. The $\mathrm{MS}$ of the developed alkaline degradate represented a molecular ion peak at $\mathrm{m} / \mathrm{z}=399$ with $44.89 \%$. Degradation with alkaline conditions, suggesting a lower molecular ion peak of 77 units. This implies phenyl group loss. In acid degradation, the molecular ion peak was shown by electronic ionization mass at $\mathrm{m} / \mathrm{z}=346$, with high intensity $(56.99 \%)$, this indicate decreasing in molecular ion peak equal 130 unit referring to loss of isopropyl d-alaninate moiety as shown in Figure 6 (a-c). In conclusion, the postulated alkaline degradate compound produced by the elimination of the phenyl moiety to carry the free phosphoryl group and the established acid degradate compound formed by isopropyl alaninate moiety removal to provide the free phosphate group from the previous conditions of IR and Electronic Ionization mass analyses. The system of degradation has been shown in scheme1.

\subsection{Method optimization}

Severe overlapping in spectrum consider the major problem presented during the assay of tenofovir alafenamide in presence of its alkaline degradate; as shown in Figure 1.

However; this overlapping can be resolved upon applying $\mathrm{DW}, \quad{ }^{1} \mathrm{D}, \quad \mathrm{RD}$ and ${ }^{1} \mathrm{DR}$ UV-spectrophotometric methods for determination of tenofovir alafenamide in presence of its alkaline degtadate. However; the presence of its acidic degradate, hindered the assigning of the drug by these methods. Thus, they were only used for determination of the dug in relation to its alkaline degradate.

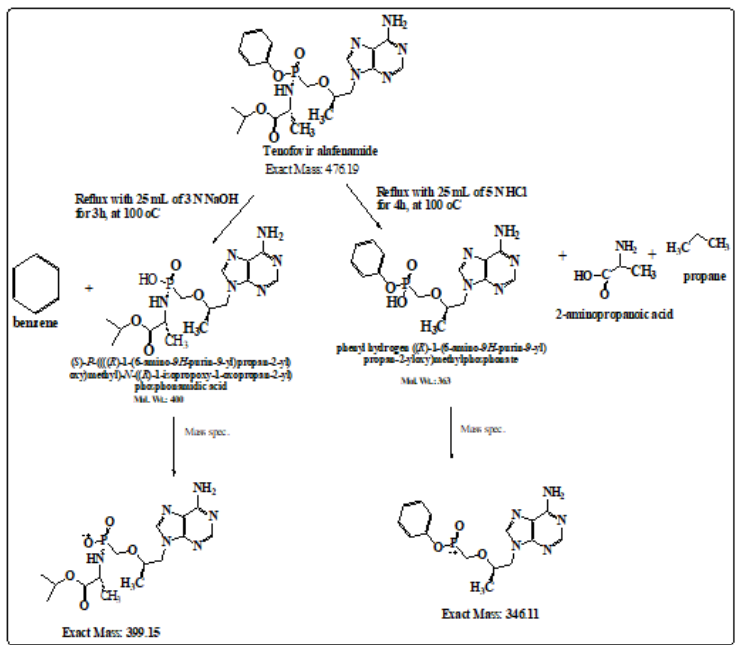

Scheme 1. Suggested degradation pathway of tenofovir alafenamide.
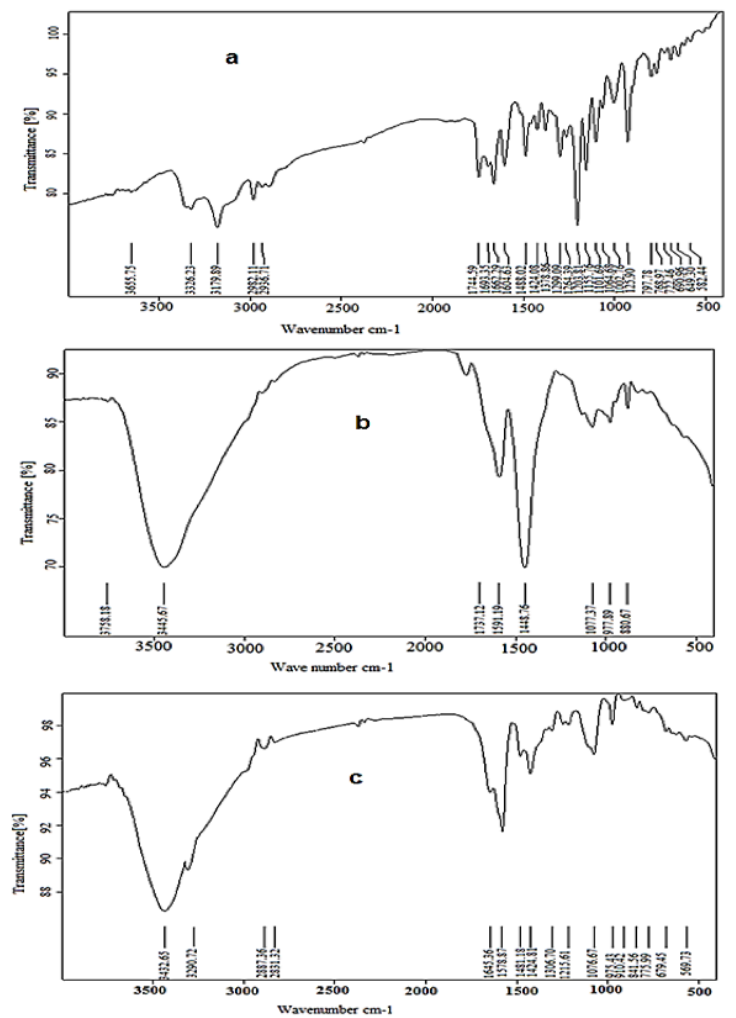

Figure (5): IR Spectra of (a) intact tenofovir alafenamide, (b) Its alkaline degradate and (c) its acidic degradate(c)) on $\mathrm{KBr}$ disc.

\subsubsection{Dual wavelength (DW)}

Absorbance between 235.5 and $261.5 \mathrm{~nm}$ was used for estimation of tenofovir alafenamide in presence of alkaline degradate which showed zero absorbance. Method of dual wavelength is simple, accurate and easy method as it doesn't need any particular 
software programs and doesn't require additional processing.

\subsubsection{First derivative $\left({ }^{1} D\right)$}

${ }^{1} \mathrm{D}$ - spectrophotometric method eliminated the interference in spectra between intact drug and its alkaline degradate at $274 \mathrm{~nm}$, using $\Delta \lambda=8 \mathrm{~nm}$ and a $\mathrm{SF}=20$.

\subsubsection{Ratio Difference (RD)}

In this method, good choice of the divisor concentration was of high importance. Thus, various concentrations of alkaline degradate were tried as a divisor $\left(10,15,20\right.$ and $\left.25 \mu \mathrm{g} \mathrm{mL}^{-1}\right)$. The preferable one was $10 \mu \mathrm{g} \mathrm{mL}^{-1}$, as it gave better results with minimum noise in accordance with good selectivity. So, absorbance was measured between 261.5 and $252 \mathrm{~nm}$ for determination of pure drug in presence of its alkaline degradation product by using $10 \mu \mathrm{g} \mathrm{mL}^{-1}$ of the later as a divisor to obtain the ratio spectra.

4.2.4. Method of first Derivative of Ratio Spectra $\left({ }^{1} D R\right)$

Tenofovir alafenamide was estimated in presence of its alkaline degradate to obtain the ratio spectra by using $\left(10 \mu \mathrm{g} \mathrm{mL}^{-1}\right)$ of degradate as a divisor, to get the ratio spectra. Then, the first derivative of ratio spectra with SF: 10 was obtained and finally smoothed at $\Delta \lambda 8 \mathrm{~nm}$. The amplitude of $\mathrm{DR}^{1}$ spectra of (TAF/ alkaline degradate) is measured at $275.6 \mathrm{~nm}$.

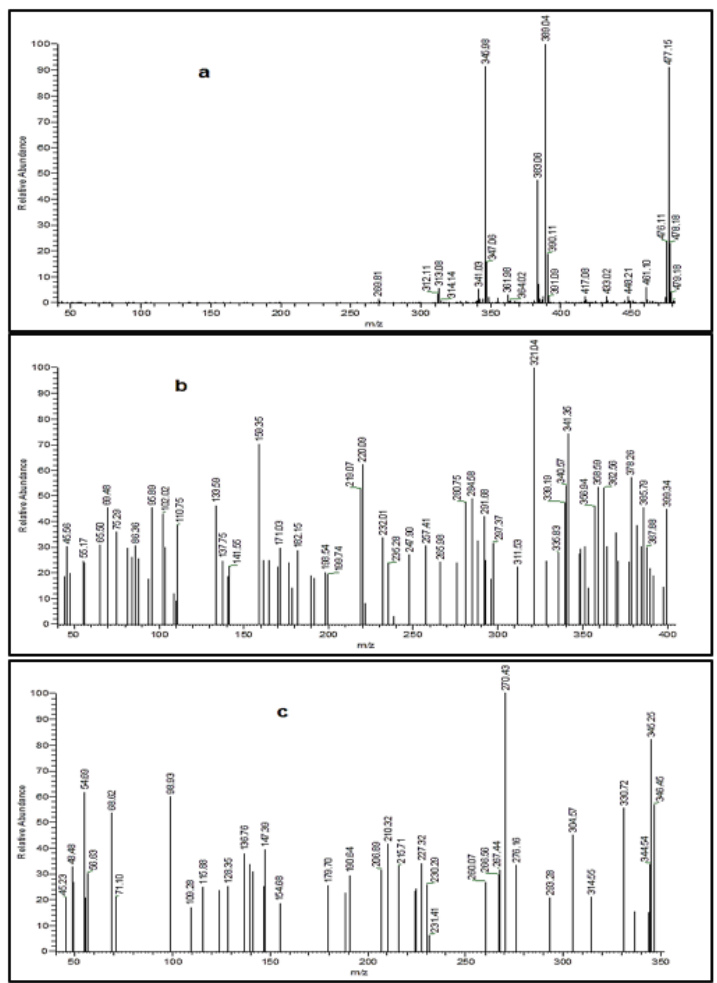

Figure (6): Mass spectra of (a) intact tenofovir alafenamide, (b) Its alkaline degradate and (c) Its acidic degradate.

\section{EVALUATION OF GREENNESS OF THE SUGGESTED METHODS}

Greenness of the suggested UVspectrophotometric methods were evaluated following to the analytical Eco-Scale which was adjusted by estimating penalty points of each step during the whole procedure. The analytical Eco-Scale has characteristics comparing with other scales because of simplicity of calculating the score and pointing out to different aspects of the environmental effect of analytical procedure in the assessment procedure ${ }^{27}$. In GAPI, a specific symbol with five pentagrams could be used to evaluate and quantify-from green through yellow to red-the low, medium and high environmental impact involved for each step of the methodology $y^{30}$. The analytical Eco-Scale value of the proposed methods was calculated and its score was 83 which was considered as an excellent green analysis as shown in Table 5. Translation of the GABI pentagrams for the proposed spectrophotometric methods and its comparison with the reported one was illustrated in Figure 7. It is evident that our developed methods are greener than the reported one with good validation parameters. So, without harmful effects on the environment, the developed procedures can be used for routine analysis of the studied drug.

\section{CONCLUSION}

The suggested study described four different UV- spectroscophotometric methods used for estimation of tenofovir alafenamide in presence of its alkaline degradate in which the degradation conditions were documented by IR and mass spectra. All of these developed methods lead to spectra resolution and confirm their strength to be used for stability indicating determination of the drug. They provide to be green, simple, accurate and economic and do not require initial pretreatment steps. Using analytical Eco-Scale and Green Analytical Procedure Index techniques, greenness evaluation of the method was carried out, demonstrating the highest greenness of the developed methods. Consequently, these methods were efficiently performed for assessment, stability studies and regular quality control analysis of tenofovir alafenamide.
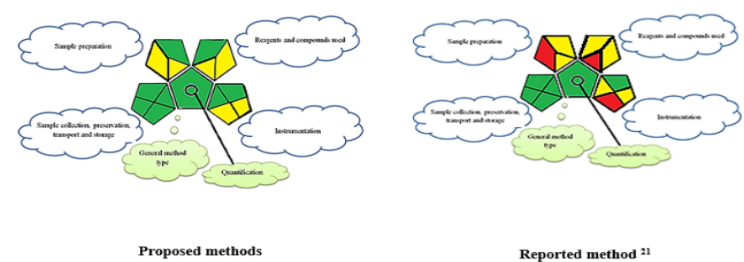

Figure (7): The green assessment profile for the proposed methods in comparison with the reported method, using the GAPI tool. 
Table 5: The penalty points of the proposed method according to the analytical Eco-Scale.

\begin{tabular}{lc}
\hline $\begin{array}{l}\text { Reagents/ } \\
\text { Instruments }\end{array}$ & Penalty points \\
\hline Methanol & 12 \\
spectrophotometer & 0 \\
\hline $\begin{array}{l}\text { Occupational } \\
\text { hazards }\end{array}$ & 0 \\
Waste & 5 \\
\hline Total pps & $\Sigma 17$ \\
Eco-Scale & 83 \\
& Excellent \\
& green \\
& analysis \\
\hline
\end{tabular}

List of Abbreviations: TAF: Tenofovir alafenamide; UV: Ultraviolet; HIV: Human Immunodeficiency; NRTIs: Nucleoside Reverse Transcriptase Inhibitors; SF: Scaling Factor; DW: Dual Wavelength; ${ }^{1} \mathrm{D}$ : First Derivative; RD: Ratio Difference; ${ }^{1} \mathrm{DR}$ : First Ratio Spectra Derivative; ICH: International Harmonization Meeting; LOD: Limit of Detection; LOQ: Limit of Quantification; MS: Mass spectroscopy; RSD: Relative Standard Deviation; SD: Standard Deviation; ICH: International Conference on Harmonization; GAPI: Green Analytical Procedure Index.

Funding: There is no funding for the authors to develop this research.

Conflicts of interests: Authors also stated that there is no conflict of interest.

\section{Ethical statement: NA}

Authors' contributions: All authors had full access to all the information and took responsibility for data integrity and data analysis accuracy. Author SAR designed the study and wrote the protocol. Author NSS performed the experimental work and scanned the literature. Authors NSS and ZAN wrote the manuscript's first draught. Authors SAR and ZAN supervised the work. The final manuscript was read and accepted by all the contributors.

\section{REFERENCES}

1. Dobariya P, Mrunalshirsat. HPLC method development and validation for estimation of tenofovir alafenamide hemifumarate in bulk and simultaneous estimation of tenofovir alafenamide and emtricitabine in combined tablet dosage form. IJRSR. 2020; 11(06): 38970-38974.

2. Kumar P, Jacob J, Ajina K. Spectroscopic estimation of tenofovir alafenamide an antiretroviral drug. J Pharm and Tech. 2016; 9(5): 538-540.
3. Badgujar BP, Mahajan MP, Sawant SD. Development and validation of a simple spectrophotometric method for the determination of tenofovir alafenamide in bulk form, Int $\mathrm{J}$ Pharma Res \& Rev. 2017; 6(4):1-5.

4. Abdel Hay MH, Gazy AA, Shaalan RA, Ashour HK. Simple spectrophotometric methods for determination of tenofovir fumarate and emtricitabine in bulk powder and in tablets. J Spectro. 2013; 1-7.

5. Shelke A, Shinde M, Mogal R, Sable R, Jadhav A. Application of UV spectrophotometric methods for simultaneous estimation of emtricitabine and tenofovir alafenamide fumarate in bulk. AJPTech. 2018; 8 (2):103-107.

6. Badgujar BP, Mahajan MP, Sawant SD. Development and validation of RP-HPLC method for the simultaneous estimation of tenofovir alafenamide and emtricitabine in bulk and tablet dosage form. Int $\mathrm{J}$ ChemTech Res. 2017; 10 (5): 731-739.

7. Akram NMD, Umamahesh M. A new validated RP-HPLC method for the determination of emtricitabine and tenofovir AF in its bulk and pharmaceutical dosage forms. JCPS. 2017; 10(4): 54-59.

8. Dudekula B, Ravichandran C, Ramachandra C, Devanna N. Development and validation of RP-HPLC method for the simultaneous estimation of emtricitabine and tenofovir alafenamide in bulk and tablet dosage form. EJBPS. 2017; 4 (10):663-668.

9. Meenakshi R, Sunder RS. Method development and validation by RP-HPLC for simultaneous estimation of emtricitabine, bictegravir, tenofovir alafenamide in fixed dosage form. IAJPS. 2018; 5 (7): 7123-7131.

10. Gandla K, Majutha N, Kumar DS. A novel RP-HPLC method for the simultaneous estimation of tenofovir alafenamide and emtricitabine in bulk and combined tablet dosage forms. Inno Int J of Medical \& Pharm Sci. 2018; 3(6): 1-4.

11. Kokkirala TK, Suryakala D. RP-HPLC method development and validation for the estimation of emtricitabine, bictegravir and tenofovir alafenamide in bulk and pharmaceutical dosage form. JTUSCI. 2019; 13 (1): 1137-1146.

12. Kalamkar CS, Bhawae SB. Development and validation of RP-HPLC method for the 
simultaneous estimation of tenofovir alafenamide fumarate and emtricitabine in bulk and tablet dosage form. JDDTAO. 2019; 9(3): 236-242.

13. Deepthi VS, Narendra D. Method Development and validation for simultaneous estimation of emtricitabine, bictegravir and tenofovir alafenamide by RP-HPLC. Int J Pharm Sci Rev Res. 2019; 58(2): 54- 59.

14. Mastanamma SK, jyothi JA, Sadulu P, varalakshmi $\mathrm{M}$. Development and validation of RP-HPLC method for simultaneous estimation of lamivudine, tenoforvir alafenamide fumarate, dolutegravir bulk and their combine dosage form. Pharmaceutical Methods. 2018; 9 (2): 49-55.

15. Kumar K, Nagpal KL, Kumar J. Quantitative analysis of bictegravir, emtricitabine, tenofovir alafenamide in human plasma by HPLC-MS/MS and its application to bioequivalence study in healthy subjects. AJMPS. 2018; 6(2): 75-87.

16. Mingxing $\mathrm{H}$, Wang $\mathrm{Q}$, Xiuying $\mathrm{M}$, et al. Rapid and Sensitive LC Method for Determination of diastereomeric purity of tenofovir alafenamide. Chromatographia. 2014; 77(19): 1399-1403.

17. Andrew JO, Haglera Gene E, et al. Development and validation of an LC-MS/MS assay for tenofovir and tenofovir alafenamide in human plasma and cerebrospinal fluid. JPBA. 2018; 156: 163-169.

18. Appala R, Macharla VR, Shyam T. Bioanalytical method development and validation for simultaneous determination of bictegravir tenofovir and emtricitabine in human plasma by LCMS/MS. WIPPS. 2018; 7(12): 441-463.

19. Srujani C, Sowmya DK, Murthy VSN, Rani AP. Development and validation of stability indicating UV spectrophotometric method for the estimation of tenofovir in its bulk and pharmaceutical dosage form. Der Pharmacia Lett. 2015; 7 (9):177-185

20. Shinde MP, Patil A, Bendale AR, et al. Development of a UV-spectrophotometric method for study of degradation profile of tenofovir alafenamide. Int $\mathrm{J}$ Pharm Chem and Anal. 2018; 5(3): 144-146.

21. Aggarwal NN, Bhat KI, Jacon JT. Stability indicating assay method development and validation for tenofovir alafenamide fumarate by RP-HPLC. Pharm Anal Acta. 2018; 9(12):1-6.
22. Mastanamma SK, Reddy DV, Saidulu P, Varalakhim M. Development and validation of stability indicating RP-HPLC method for the simultaneous estimation of emtricitabine tenofovir alafenamide bulk and their combined dosage form. J Chem Pharm Res. 2017; 9(9): 70-80.

23. Saidulu P, Mastanamma SK, Suresh PV, Prameela RA. Development and validation of stability-indicating HPLC-DAD method for simultaneous determination of emtricitabine, rilpivirine, and tenofovir alafenamide in bulk and their pharmaceutical dosage forms. Int. J ChemTech Research. 2018; 11(09): 329-339.

24. Sneha M, Valli Kumari RV. Stability indicating RP-HPLC method for simultaneous estimation of emtricitabine, bictegravir and tenofovir alafenamide in bulk and formulation. IJPAR. 2019; 8(3): 281-292.

25. Deepthi R, Gowri SD. Novel Stress indicating RP-HPLC method development and validation for the simultaneous estimation of bictegravir, emtricitabine and tenofovir alafenamide. IAJPS. 2019; 06(06): 13282-13291.

26. Pasha SI, Varanasi MB, Mohammed I. Stability indicating RP-UPLC-PDA method development, validation of multi drug combination of emtricitabine, tenofovir alafenamide and rilpivirine in bulk drug and its tablet formulation. Orient J Chem. 2017; 33(2): 925-929.

27. Tobiszewski M, Marc M, Galuszka A, Namiesnik J. Green chemistry metrics with special reference to green analytical chemistry. Molecules. 2015; 20: 10928-10946.

28. ICH, Q2 (R1). Validation of analytical procedures: Text and methodology, Geneva; 2005 .

29. Armitage P, Berry G. Statistical methods in medical research, 3rd ed. Oxford (UK): Blackwell; 1994.

30. Płotka- Wasylka J. A new tool for the evaluation of the analytical procedure: green analytical procedure index. Talanta. 2018; 181: 204-209. 